\title{
Sensitivity of detecting Chlamydia trachomatis elementary bodies in smears by use of a fluorescein labelled monoclonal antibody: comparison with conventional chlamydial isolation
}

\author{
BRENDA J THOMAS, ${ }^{*}$ RT EVANS, ${ }^{*}$ DA HAWKINS,${ }^{*} \dagger$ D TAYLOR-ROBINSON* \\ From the *Division of Sexually Transmitted Diseases, MRC Clinical Research Centre, Watford Road, \\ Harrow, Middlesex HA1 3UJ, and the †Praed Street Clinic, St Mary's Hospital, Paddington, London W2
}

SUMMARY Commercially produced fluorescein labelled monoclonal antibodies for the detection of Chlamydia trachomatis have recently become available. One is for detecting inclusions in cell culture (culture confirmation) and the other for detecting elementary bodies in smears from potentially infected sites. We have compared the two monoclonal antibodies with our routine isolation method, which utilises Giemsa staining of cycloheximide treated McCoy cell cultures. The culture confirmation system offered no advantages over Giemsa staining for the detection of inclusions in cell monolayers. By contrast, using monoclonal antibody to detect elementary bodies in smears was much quicker and simpler and slightly more sensitive than isolation of chlamydiae in cell culture. For specimens from seven babies with conjunctivitis and from 35 female contacts of men with non-gonococcal urethritis, there was complete agreement between the results of detecting inclusions in culture and those of seeking elementary bodies in smears. For samples from 100 men with non-gonococcal urethritis and from 100 men with gonorrhoea there was $99 \%$ and $94 \%$ agreement, respectively, between the results of the two tests. Other aspects and possible uses of the new detection system are discussed.

Chlamydia trachomatis is detected routinely by isolation in cell culture and staining the inclusions with iodine or Giemsa stain.' A result may be obtained $48 \mathrm{~h}$ after the specimen reaches the laboratory using this technique. Chlamydiae, however, are labile organisms and correct storage and transport of specimens to the laboratory are crucial for successful isolation. In addition, the sensitivity of cell culture techniques depends on many factors, particularly culture medium constituents and the correct identification of stained inclusions.

The ability to detect chlamydial elementary bodies reliably in smears of exudate from potentially infected sites could render chlamydial isolation and all its associated problems unnecessary. Staining elementary bodies of $C$ trachomatis with a fluorescein labelled monoclonal antibody of high titre provides a means of accomplishing this rapidly. We have assessed such a procedure in tests on smears of

Accepted for publication 28 March 1984 exudate from several groups of patients by comparing the sensitivity and specificity of the method with that of isolating chlamydiae in cycloheximide treated McCoy cells and staining the resulting inclusions with Giemsa stain. In addition, staining inclusions with a fluorescein labelled monoclonal antibody (culture confirmation) has been compared with the Giemsa staining technique.

\section{Material and methods}

PATIENTS

One hundred men with untreated non-gonococcal urethritis and 100 men with untreated gonorrhoea were studied. Non-gonococcal urethritis was diagnosed if there were $\geqslant 10$ polymorphonuclear leucocytes/high power microscope field $(\times 800)$ in a Gram stained smear of urethral discharge, diplococci were not seen, and subsequent culture for gonococci was negative. Gonorrhoea was diagnosed by the presence of intracellular Gram negative diplococci in a smear and was confirmed by culture. In 
addition, seven babies with neonatal ophthalmia who had not responded to chloramphenicol treatment and 35 female contacts of men with nongonococcal urethritis have been examined to date, as part of a larger, continuing study.

\section{MONOCLONAL ANTIBODIES}

These were obtained from Syva UK (Maidenhead, Berks). Smears of exudate were examined using the "MicroTrak Chlamydia trachomatis direct fluorescent antibody reagent" and culture confirmation tests were performed using the "MicroTrak Chlamydia culture confirmation fluorescent monoclonal antibody." Both reagents contain fluorescein labelled monoclonal antibodies specific to the principal membrane protein of $C$ trachomatis and Evans blue counterstain in a protein stabilised buffer solution.

\section{CONTROL PREPARATIONS}

These were also obtained from Syva UK. Positive control slides comprised fixed smears of mammalian cells and $C$ trachomatis elementary bodies which were similar in appearance to that of chlamydia positive samples; negative control slides comprised fixed smears of mammalian cells only.

\section{PREPARATION OF SMEARS}

Microscope slides were sprayed with polytetrafluoroethylene from an aerosol can, leaving a masked area of $13 \mathrm{~mm}$ diameter uncoated for application of the smear.

Urethral material was obtained by inserting an ENT swab (MW142; Medical Wire and Equipment Co, Cosham, Wilts) $3-5 \mathrm{~cm}$ into the urethra. Cervical specimens were obtained, after removing excess discharge, by inserting a polyurethane sponge swab into the endocervical canal and rotating it to remove epithelial cells. Eye swabs were obtained, after removing purulent discharge, by everting the lower lid and firmly drawing an ENT swab along the lower conjunctival surface.

A smear was made by rubbing the swab, immediately after it had been taken, firmly and evenly over the whole uncoated area so that some material was visible on the slide. The smear'was allowed to dry and was then fixed immediately by covering the area with methanol for $5 \mathrm{~min}$, or until it had evaporated, without agitation. If the smears were not stained immediately they were covered with aluminium foil, stored briefly at $4^{\circ} \mathrm{C}$ if necessary, and at $-20^{\circ} \mathrm{C}$ as soon as possible thereafter until staining.

\section{CHLAMYDIAL ISOLATION}

After a smear had been made, the swab was immediately agitated vigorously and expressed in $1.0 \mathrm{ml}$ of sucrose-phosphate (2SP) medium with antibiotics. ${ }^{2}$ This was snap frozen and stored in liquid nitrogen. Chlamydiae were isolated subsequently in cycloheximide treated McCoy cells as described previously. ${ }^{2}$ Each specimen was inoculated into two cell monolayer cultures. After incubation at $37^{\circ} \mathrm{C}$ for $48 \mathrm{~h}$ both monolayers were fixed in methanol; one was stained with Giemsa and the other by the "Micro Trak" culture confirmation reagent.

\section{STAINING AND EXAMINATION OF SMEARS}

Before staining with monoclonal antibody, fixed smears which had been stored at $4^{\circ} \mathrm{C}$ or $-20^{\circ} \mathrm{C}$ were allowed to reach room temperature. Thirty microlitres of the "MicroTrak" direct monoclonal antibody were spread over the smear, and the slide was incubated at $37^{\circ} \mathrm{C}$ for $15 \mathrm{~min}$ in a moist chamber. Thereafter, excess reagent was removed by immersing the slide in distilled water; for a few specimens an extra short wash in distilled water, with stirring, was necessary. Excess water was removed by blotting around the smear with tissue or with filter paper. The smear was mounted under a coverslip with "MicroTrak chlamydia direct specimen mounting fluid" and examined with a Nikon L-Ke microscope fitted with an epifluorescence attachment.

\section{CULTURE CONFIRMATION}

Fixed cell monolayers on coverslips were removed from the culture tubes. Each coverslip was then attached to a microscope slide, cells uppermost, with Diatex (Raymond Lamb Ltd, London). Thirty microlitres of the "MicroTrak" culture confirmation monoclonal antibody were spread over the monolayer, and the slide was incubated at $37^{\circ} \mathrm{C}$ for $15 \mathrm{~min}$ in a moist chamber. The coverslip was washed in distilled water from a wash bottle to remove excess reagent and then washed again in distilled water for 10-15 min with stirring. It was blotted to remove excess water and mounted in PBS/glycerol FA mounting fluid (Difco Laboratories) under a second coverslip. Specimens were examined for fluorescing inclusions with a Nikon L-Ke microscope fitted with an epifluorescence attachment.

\section{METHOD OF RECORDING ELEMENTARY BODIES AND INCLUSIONS}

All the smears were coded and then read by one observer (BJT), who also examined coded Giemsa stained cell monolayers at a later date. All specimens for isolation were processed by one person (RTE), who also examined coded cell monolayers by the culture confirmation technique.

The numbers of elementary bodies in smears and inclusions in cell monolayers were estimated and recorded using the following scale: $\pm 1-10 ;+11-$ 
Table 1 Comparison of the sensitivity of staining inclusions in cell monolayers by the culture confirmation (CC) monoclonal antibody with that of staining by Giemsa

\begin{tabular}{|c|c|c|c|c|c|c|c|}
\hline \multirow[t]{2}{*}{ Patient group } & \multirow[t]{2}{*}{ No of patients } & \multicolumn{4}{|c|}{ No of patients whose smears were } & \multirow{2}{*}{$\begin{array}{l}\text { Total positive } \\
(\%)\end{array}$} & \multirow{2}{*}{$\begin{array}{l}\text { Agreement } \\
\text { between tests } \\
(\%)\end{array}$} \\
\hline & & $\begin{array}{l}\text { Giemsa- } \\
\text { CC- }\end{array}$ & $\begin{array}{l}\text { Giemsat } \\
\text { CC }+\end{array}$ & $\begin{array}{l}\text { Giemsat } \\
\text { CC }-\end{array}$ & $\begin{array}{l}\text { Giemsa- } \\
\text { CC+ }\end{array}$ & & \\
\hline $\begin{array}{l}\text { Men with NGU } \\
\text { Men with gonorrhoea } \\
\text { Female contacts of men }\end{array}$ & $\begin{array}{l}90 \\
99\end{array}$ & $\begin{array}{l}62 \\
76\end{array}$ & $\begin{array}{l}28 \\
19\end{array}$ & $\begin{array}{l}0 \\
2\end{array}$ & $\begin{array}{l}0 \\
2\end{array}$ & $\begin{array}{l}31 \\
23\end{array}$ & $\begin{array}{r}100 \\
96\end{array}$ \\
\hline $\begin{array}{l}\text { with NGU } \\
\text { Babies with conjunctivitis }\end{array}$ & $\begin{array}{r}35 \\
6\end{array}$ & $\begin{array}{r}26 \\
3\end{array}$ & $\begin{array}{l}9 \\
3\end{array}$ & $\begin{array}{l}0 \\
0\end{array}$ & $\begin{array}{l}0 \\
0\end{array}$ & $\begin{array}{l}26 \\
50\end{array}$ & $\begin{array}{l}100 \\
100\end{array}$ \\
\hline
\end{tabular}

NGU $=$ non-gonococcal urethritis.

$100 ;++101-1000 ;+++1001-10000 ;++++$ $>10000$.

INTERPRETATION OF DIRECT TEST RESULTS Syva recommend in the information accompanying the antibody that only smears containing $\geqslant 10$ elementary bodies should be considered positive. In order to assess the validity of this recommendation, the sensitivity of the direct test was calculated by regarding as positive (i) only those smears containing $\geqslant 10$ elementary bodies in comparison with (ii) any smear containing $\geqslant 1$ elementary body.

\section{Results}

COMPARISON OF THE SENSITIVITY OF THE CULTURE CONFIRMATION TECHNIQUE WITH THAT OF GIEMSA STAINING

There was complete agreement between the results of the two staining techniques for specimens from men with non-gonococcal urethritis, female contacts of men with non-gonococcal urethritis, and babies with sticky eyes (Table 1). Thus $31 \%, 26 \%$, ando $50 \%$ of patients in these groups, respectively, werew positive by both staining methods. The agreement $-v$ between the results of the two techniques for speci- $\infty$ mens from men with gonorrhoea was a little lower, $\vec{N}$ at $96 \%$. Two specimens each had only one inclusion? in the Giemsa stained monolayer, but none by the culture confirmation method. For two other speci- $\subseteq$ mens, culture confirmation was recorded as + and staining of smears (see below) showed elementary $\overrightarrow{0}$ bodies at the + level also. However, inclusions were + not detected by Giemsa staining in either specimen. Such obvious positive results for the cultures confirmation and smear tests suggest that the negative results obtained for the Giemsa stained cellsa were probably due to technical error.

The majority of cell cultures (55/63) which stained positively by the culture confirmation tech-o극 nique had either the same number of inclusions as the corresponding Giemsa stained preparations or a

lable 2 (comparison of the relative numbers of inclusions in cell monolayers stained by the culture confirmation (CC) monoclonal antibody or by Giemsa

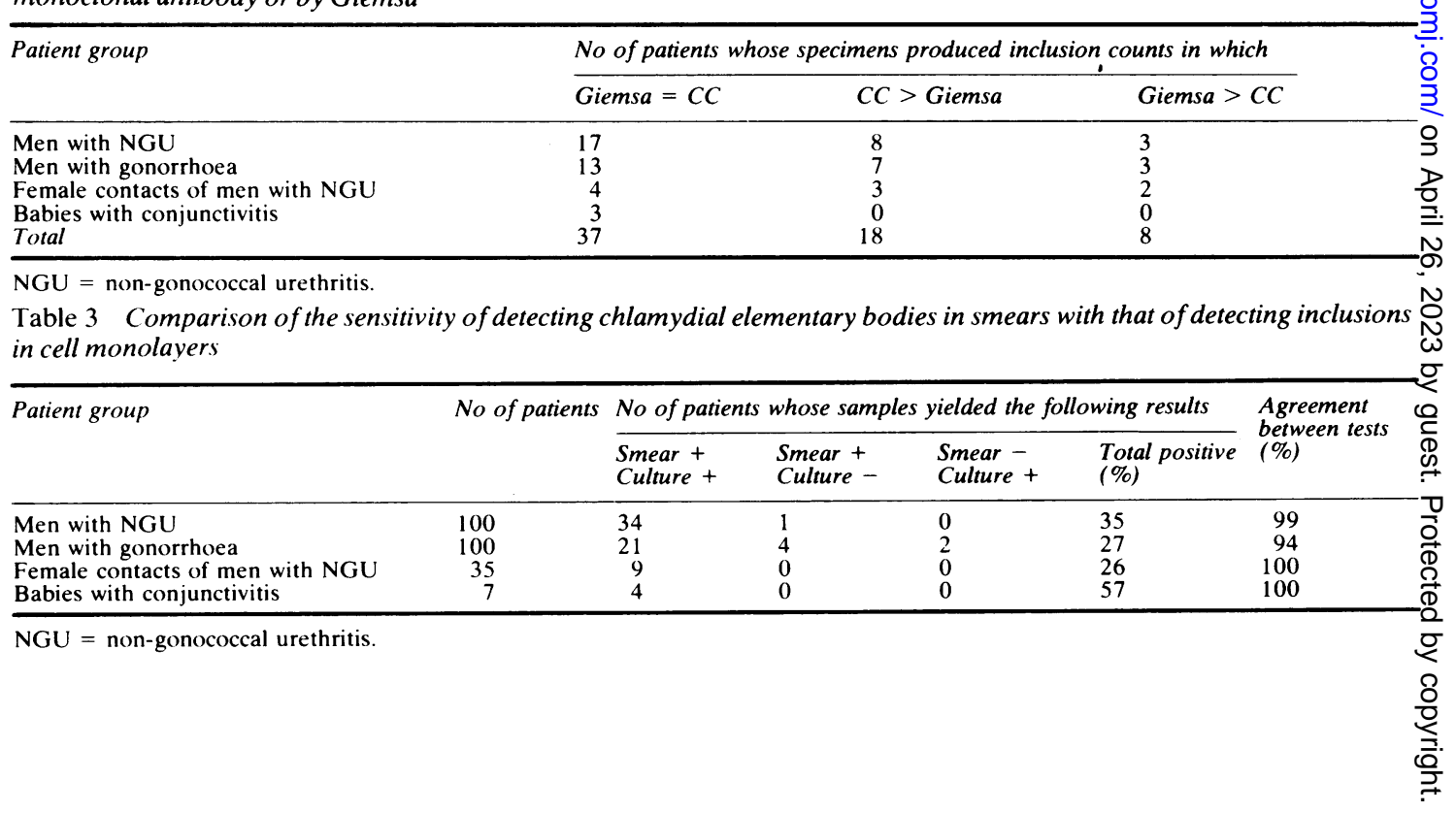


Table 4 The relative numbers of elementary bodies ( $E B s)$ seen in smears and inclusions seen in cell monolayers

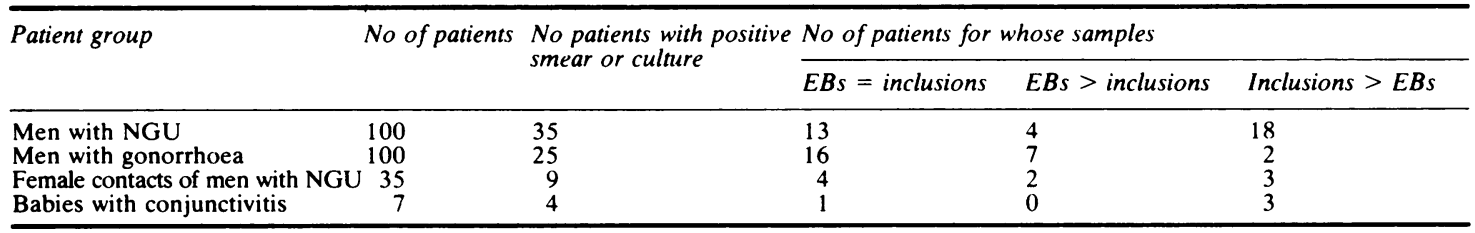

NGU $=$ non-gonococcal urethritis.

greater number (Table 2).

It was notable also that $17(74 \%)$ of 23 specimens from men with gonorrhoea who were chlamydia culture positive were recorded as either \pm or + on the scale of inclusion counts, whereas specimens from only $12(43 \%)$ of 28 men with non-gonococcal urethritis yielded this low number.

\section{DETECTION OF CHLAMYDIAE DIRECTLY IN \\ SMEARS OR BY CULTURE (CULTURE \\ CONFIRMATION OR GIEMSA STAINING)}

Elementary bodies were detected directly in smears of exudate from $35 \%$ of men with non-gonococcal urethritis, $25 \%$ of men with gonorrhoea, $26 \%$ of female contacts of men with non-gonococcal urethritis, and $57 \%$ of babies with conjunctivitis (Table 3 ). By comparison, specimens from $34 \%, 23 \%$, $26 \%$, and $57 \%$ of patients in the same groups, respectively, produced chlamydial inclusions in culture.

Twelve specimens were not tested by the culture confirmation technique so that a comparison between the results of smear tests and culture for these is based only on Giemsa staining. There was agreement between the smear and culture results for $99 \%$ of the specimens from men with non-gonococcal urethritis; in the single discrepancy, the smear was recorded as \pm but no inclusions were detected in culture. In men with gonorrhoea, the agreement between smear and culture results was slightly less at $94 \%$ - that is, there was disagreement between the results of tests on six specimens. Small numbers of inclusions $( \pm)$ were seen in cultures of two of these, but the smears were negative. All of the remaining four were negative on culture, but three produced a \pm result and the fourth a ++ result in smears. There was complete agreement between the results of smear and culture tests on all cervical and eye specimens (Table 3 ).

Table 4 shows a comparison of the number of elementary bodies seen in smears and the number of inclusions seen in the corresponding cell monolayers. There was no correlation between the two. Specimens from men with non-gonococcal urethritis, however, produced more inclusions than elementary bodies more often than specimens from men with gonorrhoea. Overall, in only a minority of specimens was the number of fluorescent elementary bodies in the smear greater than the number of inclusions which they produced in culture.

As seen previously for inclusions in culture, there was a notable difference between the numbers of elementary bodies seen in urethral smears from men with non-gonococcal urethritis and from those with gonorrhoea. Ten (40\%) of 25 positive smears from men with gonorrhoea were recorded as \pm , whereas only seven $(20 \%)$ of 35 positive smears from men with non-gonococcal urethritis were recorded at this low level.

\section{SENSITIVITY OF THE TEST ON SMEARS IF ONLY THOSE CONTAINING $\geqslant 10$ ELEMENTARY BODIES WERE CONSIDERED POSITIVE}

If smears recorded as having \pm elementary bodies are considered to be negative, the chlamydial carriage rate within the groups and the agreement between the results of the smear test and culture are reduced considerably (Table 5). Thus, the chlamydial carriage rate in men with non-gonococcal urethritis is reduced from $35 \%$ to $28 \%$, in men with

Table 5 Sensitivity of detecting elementary bodies (EBs) in smears when only $\geqslant 10$ EBs/smear is considered positive

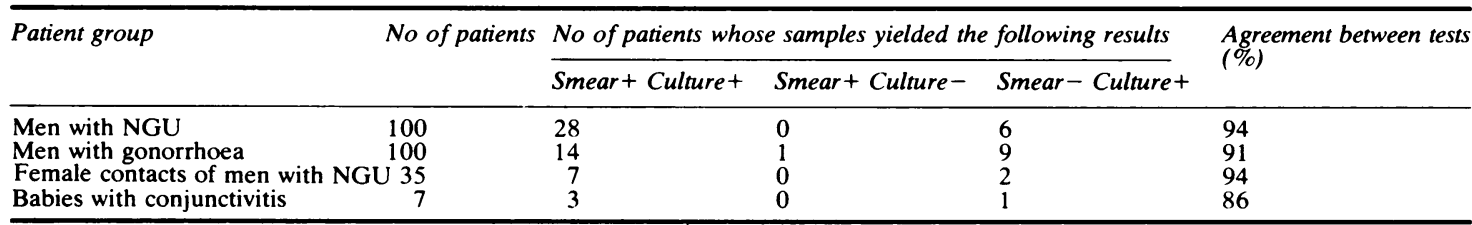

NGU $=$ non-gonococcal urethritis. 
gonorrhoea from $25 \%$ to $15 \%$, in female nongonococcal urethritis contacts from $26 \%$ to $20 \%$, and in babies with conjunctivitis from $57 \%$ to $43 \%$. The corresponding agreements between the two detection methods are reduced from $99 \%$ to $94 \%$, $94 \%$ to $90 \%, 100 \%$ to $94 \%$, and $100 \%$ to $86 \%$, respectively.

\section{Discussion}

The culture confirmation technique using a fluorescein labelled monoclonal antibody offers little advantage over Giemsa staining for the detection of $C$ trachomatis inclusions in cell monolayers. The antibody was not sufficiently potent to detect inclusions early, as we had done previously ${ }^{2}$ when using serum from a patient with lymphogranuloma venereum. However, it provided a method which was a little more sensitive than Giemsa staining in terms of the numbers of inclusions which were recorded for some specimens. Despite this, there were only four instances in which there was disagreement between the results of fluorescent antibody and Giemsa staining. Two were cases in which there appeared to be only one inclusion and the results of two may have suffered as a consequence of technical error. Thus no dramatic improvement in chlamydial isolation rates would ensue if culture confirmation by use of the monoclonal antibody were employed routinely. The extra expense over Giemsa staining would also be a disadvantage for routine laboratories.

By contrast, the identification of chlamydial elementary bodies directly in smears by use of the monoclonal antibody is much quicker and simpler and a little more sensitive than cell culture techniques. In addition, a major advantage of this method is the elimination of problems of storage of specimens and their transport to laboratories, which may be some distance from clinics.

The presence or absence of chlamydiae in a fixed smear can be determined within 30 min of a specimen being obtained from a patient. Such speed may be unnecessary, however, and specimens may equally well be stored at $4^{\circ} \mathrm{C}$ or $-20^{\circ} \mathrm{C}$ until a suitably large batch has been amassed for testing. The technical procedure is simple. Elementary bodies stained very brightly and characteristically and their distinctive shape and green colour rendered them unmistakable against the counterstained red background of cells. Indeed, in most tests elementary bodies in clinical specimens were brighter than those in the positive control preparations. Very few intact inclusions were seen; in most smears the elementary bodies were evenly distributed. Few artefacts were stained, and these could be readily dismissed since their colour and shape were invariably different from those of the chlamydial elementary bodies.

The number of elementary bodies that could be identified with confidence was less than the number of 10 or more per smear suggested as indicating a positive result by the manufacturer. When this recommendation was adopted, chlamydial carriage rates and agreement between the two detection methods fell to unacceptable levels. Recognition of small numbers of elementary bodies was particularly important in men with gonorrhoea who had a concurrent chlamydial infection. Indeed, $44 \%$ of such patients, whose smears contained only small numbers of elementary bodies, would otherwise have been regarded as chlamydia negative.

The fact that the finding of elementary bodies in a smear rarely occurs without also detecting inclusions in culture suggests that chlamydial isolation techniques are of maximum sensitivity and that the rates of chlamydial carriage based on culture techniques are unlikely to be increased by using any other procedure. It is also interesting to note that patients do not appear to harbour large numbers of non-viable elementary bodies since elementary bodies recorded in smears only infrequently outnumbered the inclusions produced in cultures by the same specimens.

The new technique has obvious applications for research projects and, particularly, routine microbiology or venereal disease clinic laboratories. Asymptomatic female contacts of men with nongonococcal urethritis could be tested quickly and treated if necessary; men with gonorrhoea could be tested immediately for a concomitant chlamydial infection which, if present, could be treated to prevent the development of chlamydial postgonococcal urethritis; infants with conjunctivitis presenting to hospital day care or outpatient units could be tested rapidly, and both infant and mother treated immediately, if necessary. The technique has been found to be highly sensitive and specific in this laboratory but its more widespread use in clinics and associated laboratories is essential to confirm its usefulness in the situations mentioned.

We thank Dr GE Forster and Dr I Cookey for help in obtaining some of the cervical specimens.

References
' Evans RT, Woodland RM. Detection of chlamydiae by isolation
and direct examination. Br Med Bull $1983 ; 39: 181-6$.
${ }^{2}$ Thomas BJ, Evans RT, Hutchinson GR, Taylor-Robinson D.
Early detection of chlamydial inclusions combining the use of
cycloheximide-treated McCoy cells and immunofluorescence
staining. J Clin Microbiol $1977 ; 6: 285-92$.

Requests for reprints to: Dr D Taylor-Robinson, Clinical Research Centre, Division of Sexually Transmitted Diseases, Watford Road, Harrow, Middlesex HA1 3UJ, England. 